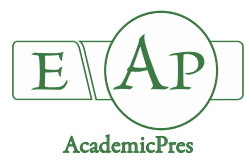

\title{
Arbuscular Mycorrhiza Improves Leaf Food Quality of Tea Plants
}

\author{
Ya-Dong $\mathrm{SHAO}^{1}$, De-Jian $\mathrm{ZHANG}^{1}$, Xian-Chun $\mathrm{HU}^{1}$, \\ Qiang-Sheng WU ${ }^{1,2,3 *}$, Chang-Jun JIANG ${ }^{2 * *}$, Xiu-Bing GAO $^{4}, \mathrm{Kamil} \mathrm{KUČA}^{3}$ \\ ${ }^{1}$ Yangtze University, College of Horticulture and Gardening, Jingzhou, Hubei 434025, \\ China;1092743294@qq.com; zhangdejian0553@126.com;360233834@qq.com;wuqiangsh@163.com(*correspondingauthor) \\ ${ }^{2}$ Anhui Agricultural University, State Key Laboratory of Tea Plant Biology and Utilization, Hefei, Anhui 230036, \\ China; jiangcj@ahau.edu.cn (**correspondingauthor) \\ ${ }^{3}$ University of Hradec Kralove, Faculty of Science, Department of Chemistry, Hradec Kralove 50003, Czech Republic; kamil.kuca@ubk.cz \\ ${ }^{4}$ Tea Research Institute, Guizhou Province Academy of Agricultural Science, Guiyang, Guizhou 550006, China; gxb527@163.com
}

\begin{abstract}
Tea (Camellia sinensis) plants inhabit arbuscular mycorrhizal fungi (AMF) in rhizosphere, whereas it is not clear whether AMF improves leaf food quality of tea plants. A potted study was conducted to determine effects of Claroideoglomus etunicatum, Diversispora spurca, D. versiformis and a mixture of the three AMF species on leaf sugar, amino acid, soluble protein, tea polyphenol, catechuic acid, and flavonoid contents of Camellia sinensis 'Fuding Dabaicha' seedlings. After 12 weeks of AMF inoculation, mycorrhizal plants recorded significantly higher shoot biomass and total leaf area, whilst the effect was ranked as C. etunicatum $>$ D. spurca $>$ mixed-AMF $>$ D. versiformis in the decreasing order. AMF treatments significantly increased leaf total amino acid concentrations, accompanied with up-regulation of amino acid synthetic enzymes genes glutamine synthetase $(C s G S)$, glutamate synthase $(C s G O G A T)$ and glutamate dehydrogenase $(C s G D H)$. Leaf glucose, sucrose, total soluble protein, tea polyphenol, catechuic acid, and flavonoid contents were significantly higher in AMF- than in nonAMF-inoculated plants. In addition, mycorrhizal inoculation notably up-regulated the expression level of leaf 3-hydroxy-3methylglutaryl coenzyme gene (CsHMGR), ascorbate peroxidase gene (CsAPX), and tea caffeine synthase 1 gene $(C s T C S 1)$. These results implied that AMF inoculation had positive effects on leaf food quality partly by means of up-regulation of relevant gene expression in 'Fuding Dabaicha' seedlings.
\end{abstract}

Keywords: soil microorganism; sucrose; symbiotic fungi; tea polyphenol; white tea

\section{Introduction}

Tea (Camellia sinensis (L.) O. Kuntze) is an important commercial crop consumed worldwide, primarily as a beverage made from the processed leaves. Tea tree growth is often affected by soil nutrient levels, temperature, pruning, and soil microbes including arbuscular mycorrhizal fungi (AMF) (Burgess and Carr, 1996; Van Lelyveld et al., 1990; Sharma and Kayang, 2017). AMF effects on plant growth have been reported in many plants, including tea plants (Aliasgharzad et al., 2011; Shao et al., 2018). Singh et al. (2008) observed AMF inhabited in tea plant rhizosphere, dominated by Acaulospora, Gigaspore, Glomus and Scutellospora. As reported by Kahneh et al. (2006), inoculation with Glomus etunicatum, $G$. intraradices and $G$. versiforme significantly increased plant growth and leaf nutrient levels in tea plants. It seems that AMF has potential capacity to improve plant growth in tea plants.
In addition to growth and nutrients, AMF inoculation also improves food quality of crops (Lingua et al., 2013). As reported by Lingua et al. (2013), AMF inoculation with Glomus sp. markedly increased the concentration of cyaniding 3-glucoside, pelargonidin 3-glucoside, and pelargonidin malonyl glucoside in strawberry fruits. Inoculation with $G$. mosseae in tomato plants had a significantly positive effect on the number of fruits, in company with the increase in amino acid abundance in the fruit, with glutamine and asparagines as the most responsive amino acids (Salvioli et al., 2012). In chili ancho, AMF treatment strongly increased carotene concentrations and xanthophylls concentrations in fruits (Mena-Violante et al., 2006). Until now, the information regarding AMF effect on food quality of tea is relatively scarce.

Food quality of tea is closely associated with relevant enzymes, including glutamine synthetase (GS), glutamate synthase (GOGAT) and glutamate dehydrogenase (GDH), 
who take part in amino acid biosynthesis pathway (Lin $e t$ al., 2012). The $G S, G O G A T$, and $G D H$ expression is important in tea quality. Previous studies also reported that AMF could regulate the expression of host plant genes (Cicatelli et al., 2012; Vangelisti et al., 2018). Chen et al. (2013) reported that inoculation with Funneliformis mosseae enhanced the expression of stress-related marker genes in cucumber. Earlier studies reported the stimulated effects of AMF on Pi transporter expression in maize (Hui et al., 2013), root tonoplast intrinsic protein gene expression in drought-stressed trifoliate orange (He et al., 2019), auxinrelated gene expression in P-stressed trifoliate orange (Liu et al., 2018), and arsenite transporter expression in rice (Chen et al., 2012). However, it is not clear whether inoculation with AMF regulates the expression levels of relative genes in tea plants involved in antioxidant protected systems (mainly ascorbate peroxidase biosynthesis), and tea quality (mainly amino acids, tea caffeine, and terpene metabolisms).

Since many studies showed a positive effect of AMF on food quality of crop plants, we here hypothesize that AMF colonization could improve food quality of tea plants through up-regulation of some potential gene expression. To confirm the hypothesis, $C$. sinensis 'Fuding Dabaicha' was selected and inoculated with AMF, and leaf food quality and relevant gene expression were analyzed.

\section{Materials and Methods}

\section{Experimental design}

The experiment was arranged in an absolutely randomized blocked design with five AMF treatments: (1) inoculation with Claroideoglomus etunicatum (W.N. Becker \& Gerd.) C. Walker \& A. Schüßler, (2) inoculation with Diversispora spurca (C.M. Pfeiff., C. Walker \& Bloss) C. Walker \& A. Schüßler, (3) inoculation with $D$. versiformis (P. Karst.) Oehl, G.A. Silva \& Sieverd, (4) mixed inoculation with $C$. etunicatum, D. spurca and $D$. versiformis (the ratio is 1:1:1), and (5) inoculation with non-AMF (non-AMF). Four replicates were conducted in each treatment and each replicate had one seedling, totaling twenty pots in this experiment.

\section{Experimental set-up}

Seeds of tea (C. sinensis 'Fuding Dabaicha') plants were sterilized with $75 \%$ of alcohol solutions for $10 \mathrm{~min}$, rinsed with distilled water, and sown into autoclaved $\left(121^{\circ} \mathrm{C}, 0.11\right.$ $\mathrm{MPa}, 1 \mathrm{~h}$ ) sands for germination under 28/20 day/night temperature conditions. After approximate one month, a two-leaf-old seedling was transplanted into a pot $(18 \mathrm{~cm}$ upper diameter $\times 11 \mathrm{~cm}$ height $\times 15 \mathrm{~cm}$ bottom diameter), where $2300 \mathrm{~g}$ of autoclaved $\left(121^{\circ} \mathrm{C}, 0.11 \mathrm{MPa}, 2 \mathrm{~h}\right)$ soils was supplied. The potted soil was collected from the 20 -yrold tea plantation $\left(31^{\circ} 15^{\prime} \mathrm{N}\right.$ and $\left.111^{\circ} 05^{\prime} \mathrm{E}\right)$ with Yichang Dayecha cultivar, which was located in the Shuiyueshi town, Xingshan, Yichang, China.

The AMF species used here included Claroideoglomus etunicatum, Diversispora spurca, and D. versiformis. A mixture of the above three AMF species was also considered as a mycorrhizal treatment. Non-AM fungal treatment received same accounts of autoclaved $\left(121^{\circ} \mathrm{C}, 0.11 \mathrm{MPa}, 1\right.$ h) inoculums plus $3 \mathrm{~mL}$ filtrate of inoculum to keep similar microbial communities, except for these AMF straits. The monospecific spores of these AMF species were propagated on white clover in the disinfested mixture of soils and sands using pot culture for 12 weeks. Mycorrhizal inoculums included spores, infected root segments, and growth substrates. For AMF inoculations, 1200 spores of mycorrhizal inoculum in each AM fungal species were applied into rhizosphere of a tea seedling in the pot.

The AMF- and non-AMF-colonized plants were grown in a greenhouse of Yangtze University campus from April 16 to July 9, 2017, where photon flux density was 948 $\mu \mathrm{mol} / \mathrm{m}^{2}$, with $28 / 23{ }^{\circ} \mathrm{C}$ average day/night temperature and $82 \%$ relative air humidity.

\section{Measurements of root colonization and growth performance \\ At harvesting, total leaves were scanned with an EPSON} Flat-Scanner (V700, Seiko Epson Corp, Japan) and analyzed with the WINRHIZO 2007d (Regent Instruments Inc., Quebec, Canada) for surface area. Subsequently, the seedlings were divided into shoot and root, and shoot biomass was measured.

Root mycorrhizal colonization was measured based on the method of Phillips and Hayman (1970). Approximately 1-2 cm root segments of each seedling were collected, stained by typan blue, and microscopically observed. The mycorrhizal colonization was calculated by the following formula: AMF colonization (\%) $=100 \times$ root length infected by AMF / total root length observed.

\section{Determinations of leaffood quality parameters}

Sucrose, glucose and fructose concentrations in leaves were determined as described by Wu et al. (2010). Total soluble protein concentrations in leaves were evaluated by the method of Bradford (1976) using bovine serum albumin as the standard. Flavonoid concentrations were determined by Cheng et al. (2004). Total amino acid concentrations in leaves were measured by the ninhydrin method outlined by Tchameni et al. (2012). Tea polyphenol concentrations in leaves were assayed by de La Rosa et al. (2011). Catechuic acid concentrations in leaves were determined by the Vanillin method using the catechuic acid as the standard (Zhao, 2010).

\section{Gene expression analysis}

The relative expression of $C s G D H, C s G S, C s G O G A T$, 3-hydroxy-3-methylglutaryl coenzyme (CsHMGR), ascorbate peroxidase $(C s A P X)$, and tea caffeine synthase 1 (CsTCSI) in leaves was analyzed by real-time quantitative PCR (qRT-PCR). Total RNA was extracted from the leaves of these plants, respectively, using an EASY spin Plus plant RNA kit (RN 38, Aidlab Biotecnolohies CO. Ltd, China). RNA samples were reverse-transcribed using the PrimeScript $^{\text {TM }}$ RT reagent kit with gDNA eraser (PK02006, Takara Bio. Inc, Japan). qRT-PCR were run on a CFX96 Real Time PCR Detection System (BIO-RAD, USA). These primers for selected genes were designed based on the Genbank (http://www.ncbi.nlm.nih.gov/genbank/) and shown in Table 1. qRT-PCR reactions were carried out in the following compositions: $3.5 \mu \mathrm{L}$ sterile water, $0.5 \mu \mathrm{L}$ 
610

cDNA, $5 \mu \mathrm{L}$ SYBR GREEN PCR Master Mix (Applied Biosystem), $0.5 \mu \mathrm{L}$ forward prime, and $0.5 \mu \mathrm{L}$ reverse prime. qRT-PCR determinations were performed on three independent biological samples with three technical replications for each sample were examined. Quantification of the gene expression was done with the $2^{-\Delta \Delta \mathrm{Ct}}$ method (Livak and Schmittgen, 2001) in which the housekeeping gene $(G A D P H)$ acted as the control. The measured transcripts were normalized to the relative expression value in non-AM plants.

\section{Statistical analysis}

All the data were analyzed with one way ANOVA (SAS 8.1v, SAS Institute, Inc., 2001) to determine significances, and the Duncan's Multiple Range Test at the 5\% level was used to compare significant differences between treatments. The Pearson's correlation coefficients were done using the Proc Corr's procedure (SAS 8.1v).

\section{Results}

\section{Root mycorrhizal colonization and leaf growth}

The mycorrhizal colonization was not found in nonAMF treatment, but in AMF-inoculated seedlings. The significantly higher root colonization among treatments was ranked as $C$. etunicatum $>$ mixed-AMF $>D$. spurca $>D$. versiformis at the decreasing order, indicating a favor of 'Fuding Dabaicha' by colonization of C. etunicatum.

In this work, compared to the non-AMF-inoculation seedling, total leaf area and shoot biomass were significantly increased by $60.0 \%$ and $107.0 \%$ after inoculated with $C$. etunicatum, by $52.8 \%$ and $81.9 \%$ with $D$. spurca, by $21.7 \%$ and $68.4 \%$ with mixed-AMF, and by $8.0 \%$ and $28.7 \%$ with D. versiformis, respectively (Table 2 ).

\section{Changes in leaffood quality}

Leaf sucrose, fructose, and glucose contents were considerably higher in AM than in non-AM seedlings, regardless of AMF treatments, except for fructose contents between $D$. versiformis and non-AMF treatments (Table 3). Compared with non-AM plants, AM plants exhibited $129.7-625.0 \%$ significantly higher leaf sucrose contents, $39.8-590.9 \%$ higher leaf fructose contents, and 66.0-117.4\% higher leaf glucose contents, respectively.

AMF inoculation conferred significantly positive effects on total amino acid, total soluble protein, tea polyphenol, catechuic acid, and flavonoid contents in 'Fuding Dabaicha' (Table 3). Compared to non-AMF plants, inoculation with C. etunicatum, D. spurca, D. versiformis and mixed-AMF significantly improved leaf tea polyphenol (69.0-168.5\%), total amino acid (0.6-52.5\%), catechuic acid (178.1$1127.4 \%)$, flavonoid (130.2-262.7\%) contents of tea plants.

Mycorrhizal tea plants showed $0.6-52.5 \%$ higher leaf total amino acid contents and 73.7-199.0\% higher total soluble protein contents, compared with non-mycorrhizal plants. It suggests that mycorrhizal symbiosis can stimulate amino acid and soluble protein synthesis in host plants.

\section{Relative expression of leaf quality genes}

Compared to the non-AMF seedling, the relative expression of leaf $C s G D H, C s G S$ and $C s G O G A T$ was significantly up-regulated by $1.73,1.77$ and 1.75 times after inoculated with C.etunicatum, by $2.58,1.82$ and 3.63 times with $D$. spurca, and by $1.27,1.32$ and 1.34 times with mixed-AMF, respectively (Fig. 1).

Mycorrhizal inoculation is notably up-regulated the relative expression of leaf $C s H M G R, C s A P X$, and CsTCS1 (Fig. 2a-c). Compared to the non-AMF-inoculated seedling, the relative expression of leaf $C s H M G R, C s A P X$ and CsTCS1 was significantly up-regulated by $2.01,2.01$ and 1.89 times after inoculated with $C$. etunicatum, by $1.52,1.79$ and 1.32 times with D. spurca, and by $1.21,1.42$ and 1.22 times with mixed-AMF, respectively.

Table 1. The specific primers of relevant genes designed for real time quantitative PCR amplification

\begin{tabular}{cccc}
\hline Gene name & Accession & $\begin{array}{c}\text { Sequence }\left(5^{\prime}-3^{\prime}\right) \\
\text {-forward }\end{array}$ & $\begin{array}{c}\text { Sequence }\left(5^{\prime}-3^{\prime}\right) \\
\text { - reverse }\end{array}$ \\
\hline$G A D P H$ & XM_002263109 & TTGGCATCGTTGAGGGTCT & CAGTGGGAACACGGAAAGC \\
$C s H M G R$ & KJ946250 & CTCTTCCTCCTCCTCCTCCT & CCTTTGTGCCCTTGGATAGT \\
$C s A P X$ & EU547804 & TTCTATCAGTTGGCTGGAGTTG & AATGGTCACATCCCTTATCGG \\
$C s G D H$ & $\mathrm{JN} 602371$ & AAGCGGCAAATCATCCTACTGA & TCGTCCCACATGAAACCTTGA \\
$C s G S$ & $\mathrm{JN} 602372$ & CCTCAGAAGCAAAGCAAGGACT & AACATCAGGGTGGCTGAAAATC \\
$C s G O G A T$ & $\mathrm{JN} 602373$ & TGCTTCAGGACGTTTTGGTGT & CATGATGTGGAGGTGGGGATAT \\
\hline
\end{tabular}

Table 2. Effects of AMF inoculation on growth of Camellia sinensis 'Fuding Dabaicha' seedlings

\begin{tabular}{cccc}
\hline Treatments & $\begin{array}{c}\text { Root mycorrhizal colonization } \\
(\%)\end{array}$ & $\begin{array}{c}\text { Shoot biomass } \\
(\mathrm{g} \mathrm{FW} / \mathrm{plant})\end{array}$ & $\begin{array}{c}\text { Total leaf area } \\
\left(\mathrm{cm}^{2}\right)\end{array}$ \\
\hline C. etunicatum & $40.23 \pm 1.65 \mathrm{a}$ & $3.54 \pm 0.13 \mathrm{a}$ & $23.95 \pm 1.17 \mathrm{a}$ \\
D. spurca & $24.94 \pm 1.55 \mathrm{c}$ & $3.11 \pm 0.05 \mathrm{~b}$ & $22.87 \pm 1.29 \mathrm{a}$ \\
D. versiformis & $15.12 \pm 1.06 \mathrm{~d}$ & $2.20 \pm 0.11 \mathrm{~d}$ & $16.18 \pm 1.23 \mathrm{c}$ \\
Mixed-AMF & $32.37 \pm 1.18 \mathrm{~b}$ & $2.88 \pm 0.04 \mathrm{c}$ & $1.22 \pm 1.01 \mathrm{~b}$ \\
Non-AMF & $0 \pm 0 \mathrm{e}$ & $1.71 \pm 0.09 \mathrm{e}$ & $14.97 \pm 1.17 \mathrm{c}$ \\
\hline Note: Data $($ means \pm SD, $n=4)$ followed by different letters in same column are significantly different at $P<0.05$.
\end{tabular}


Table 3. Effects of AMF-inoculation on leaf quality parameters content ( $\mathrm{mg} / \mathrm{plant} \mathrm{DW}$ ) of Camellia sinensis 'Fuding Dabaicha' seedlings

\begin{tabular}{|c|c|c|c|c|c|c|c|c|}
\hline Treatments & Sucrose & Fructose & Glucose & $\begin{array}{c}\text { Tea } \\
\text { polyphenol }\end{array}$ & $\begin{array}{c}\text { Total amino } \\
\text { acid }\end{array}$ & $\begin{array}{c}\text { Catechuic } \\
\text { acid }\end{array}$ & Flavonoid & $\begin{array}{c}\text { Total soluble } \\
\text { protein }\end{array}$ \\
\hline C. etunicatum & $369.0 \pm 4.8 \mathrm{a}$ & $162.8 \pm 5.2 \mathrm{a}$ & $179.8 \pm 13.3 \mathrm{a}$ & $8081 \pm 117 a$ & $1899.0 \pm 63.5 b$ & $644.4 \pm 31.1 \mathrm{a}$ & $23.76 \pm 0.66 \mathrm{a}$ & $57.22 \pm 4.91 \mathrm{a}$ \\
\hline D. spurca & $238.8 \pm 7.6 \mathrm{c}$ & $94.0 \pm 5.1 \mathrm{c}$ & $174.1 \pm 13.3 \mathrm{a}$ & $7370 \pm 166 b$ & $1986.2 \pm 41.1 \mathrm{a}$ & $276.9 \pm 22.6 \mathrm{c}$ & $15.08 \pm 0.65 \mathrm{~d}$ & $62.82 \pm 6.12 \mathrm{a}$ \\
\hline D. versiformis & $116.9 \pm 4.5 \mathrm{~d}$ & $33.0 \pm 1.3 \mathrm{~d}$ & $137.3 \pm 3.2 b$ & $5088 \pm 261 d$ & $1310.8 \pm 41.6 \mathrm{~d}$ & $146.0 \pm 10.2 \mathrm{~d}$ & $19.88 \pm 0.26 c$ & $36.50 \pm 3.42 b$ \\
\hline Mixed-AMF & $258.0 \pm 6.4 \mathrm{~b}$ & $111.0 \pm 12.7 \mathrm{~b}$ & $184.4 \pm 7.1 \mathrm{a}$ & $7037 \pm 215 c$ & $1696.0 \pm 27.6 \mathrm{c}$ & $475.5 \pm 26.0 b$ & $21.85 \pm 0.36 b$ & $42.04 \pm 2.13 b$ \\
\hline Non-AMF & $50.9 \pm 1.6 \mathrm{e}$ & $23.6 \pm 0.4 d$ & $82.7 \pm 5.8 c$ & $3010 \pm 41 \mathrm{e}$ & $1302.7 \pm 46.8 \mathrm{~d}$ & $52.5 \pm 4.2 \mathrm{e}$ & $6.55 \pm 0.20 \mathrm{e}$ & $21.01 \pm 2.61 \mathrm{c}$ \\
\hline
\end{tabular}

Table 4. Correlation coefficients between leaf food quality parameter contents and root mycorrhizal colonization in Camellia sinensis 'Fuding Dabaicha' seedlings

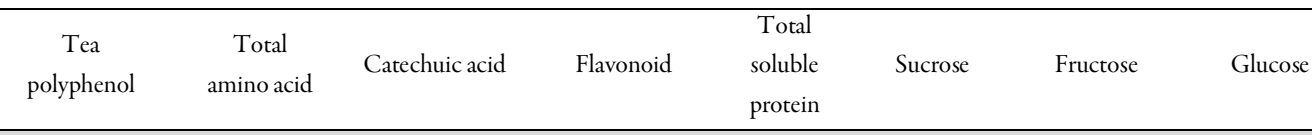

\begin{tabular}{lllllll}
\hline $\begin{array}{c}\text { Mycorrhizal } \\
\text { colonization }(\%)\end{array}$ & $0.96^{* *}$ & $0.79^{* *}$ & $0.95^{* *}$ & $0.87^{* *}$ & $0.77^{* *}$ & $0.97^{* *}$ \\
\hline Note: ${ }^{* *} P<0.01$.
\end{tabular}

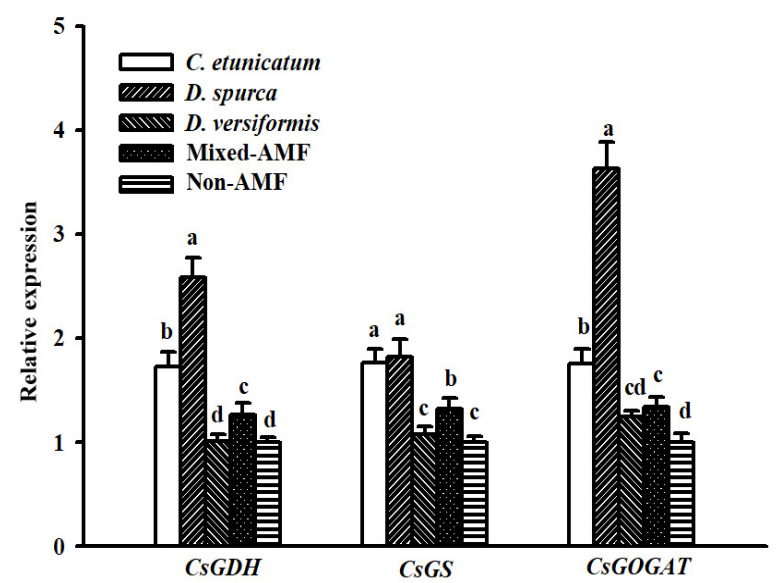

Fig. 1. Effects of AMF inoculation on relative expression of leaf $C s G D H, C s G S$, and CsGOGAT in Camellia sinensis 'Fuding Dabaicha' seedlings. Data (means $\pm \mathrm{SD}, n=3$ ) are significantly different $(P<0.05)$ followed by different letters above the bars.

\section{Discussion}

The variation in mycorrhizal colonization of tea plants was observed in different AMF treatments, which is perhaps due to the AMF specificity and the compatibility between AMF and host plants (van der Heijden et al., 1998). Meanwhile, mixed AMF was less effective than $C$. etunicatum inoculation alone, indicating competing of different strains about nutriment.

Compared to the non-AMF-inoculation seedling, total leaf area and shoot biomass were significantly increased in AMF-inoculation seedling. The result was in line with the earlier report by Fajardo et al. (2014), who observed that inoculation with Dentiscutata heterogama and Rhizophagus manihotis improved the shoot biomass and total leaf area of

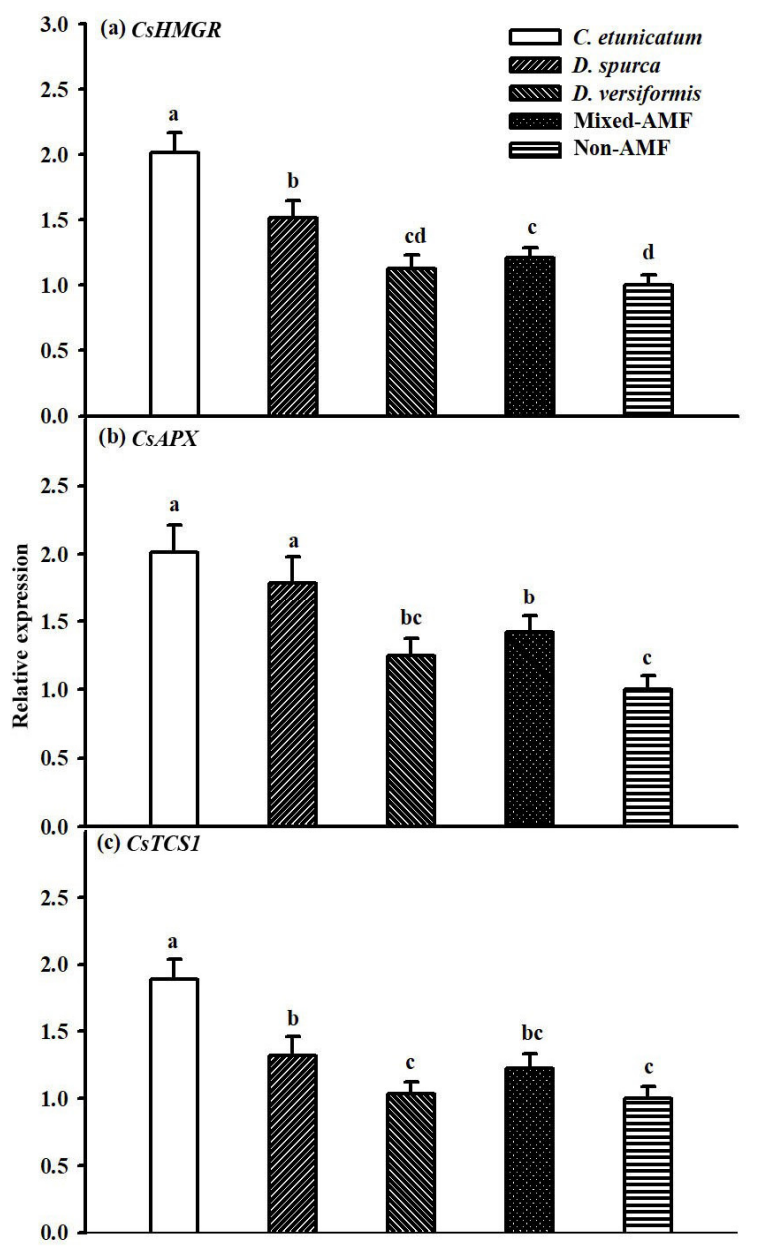

Fig. 2. Effects of AMF inoculation on relative expression of leaf CsHMGR (a), CsAPX (b) and CsTCS1 (c) in Camellia sinensis 'Fuding Dabaicha' seedlings. Data (means $\pm \mathrm{SD}, n=3$ ) are significantly different $(P<0.05)$ followed by different letters above the bars. 
612

Juglans venezuelensis plants. The enhancement of the shoot biomass and total leaf area in AM plants is often related with the improvement of nutrient acquisitions by extraradical hyphae (Camenzind and Rillig, 2013; Zou et al., 2015). Interestingly, there was an opposite result regarding root mycorrhizal colonization and plant biomass and total leaf area with mixed-AMF treatment versus $D$. spurca, indicating that the effect of single AMF was disturbed by other AMF species.

The change of leaf sugar (i.e., sucrose, fructose and glucose) is of great importance for tea plant growth and food quality (Ravnskov et al., 2003; Hartmann and Trumbore, 2016). In this work, mycorrhization plant had higher leaf sucrose, fructose, and glucose contents. A similar result was reported by Wu et al. (2015) in trifoliate orange for sucrose and glucose contents. Moreover, mycorrhizal colonization of tea plant roots was significantly positively correlated with leaf sucrose, fructose, and glucose contents. Such sugar increase under mycorrhization might be due to both improved plant nutrition and mycorrhiza-requested carbon (Cely et al., 2016).

Food quality of tea is associated with some biochemical substances imparting liquor, flavor, and aroma characteristic (Singh et al., 2010). In this work, inoculation AMF significantly improved the content of tea polyphenols, catechuic acid, flavonoid, amino acids, and soluble proteins. Tea polyphenols, catechuic acid, and flavonoid have potent antioxidant activities, which play protective roles against many diseases (Kerio et al., 2013). Tea polyphenol is the main secondary metabolity in tea, among which catechin accounts for about $70 \%$ of the total tea polyphenol (Xia et al., 2009). Zhao et al. (2014) also discovered that inoculation with $G$. mosseae resulted in an increase in the total polyphenol of Camellia sinensis. In our work, AMF inoculation significantly increased the content of catechuic acid regardless of the application of AMF species. The flavonoid has been suggested as AM signaling compounds, but also is induced by AM symbiosis (Larose et al., 2002). In a study by Zubek et al. (2015), inoculation with Rhizophagus irregularis, Funneliformis mosseae and an inoculum composed of both isolates increased root flavonoid contents of Viola tricolor. It concludes that AMF heavily accelerate the accumulation of secondary metabolites in tea plants. The relevant mechanisms are still studied in future works by means of metabolomics.

Amino acids and soluble proteins are important factors in tea food quality. Tchameni et al. (2012) inoculated Gigaspora margarita and G. mossae on cocoa (Theobroma cacao) plants and showed that the amino acids of leaves were significantly increased in mycorrhizal plants. Tomato roots inoculated with $G$. intraradices had higher contents of total amino acid in root exudates (Zubek et al., 2015). Inoculation with a mixture of Rhizoglomus intraradices and Funneliformis mosseae increased leaf soluble protein contents in lettuce (Baslam et al., 2013; Sanmartín et al., 2014). Moreover, root mycorrhizal colonization was significantly positively correlated with tea polyphenol, total amino acid, catechuic acid and total solution protein. In fact, the germinating spores of AMF can use nitrogen sources for the de novo synthesis of amino acids (Gachomo et al., 2009), which could increase protein synthesis.
$G S, G O G A T$, and $G D H$ expression is related with amino acid concentrations (Lin et al., 2012). In the present study, mycorrhizal inoculation notably up-regulated the expression level of leaf $C s G D H, C s G S$ and $C s G O G A T$. This is not in line with the result reported by Jacob et al. (2014). Meanwhile, Lin et al. (2012) reported that the expression of $G S$ was negatively related to the contents of theanine, lysine and lactamine, the expression of GOGAT was negatively related to the contents of theanine, and the expression of $G D H$ was positively related to the contents of theanine in tea plants. Therefore, the research on change of amino acid components needs further experiments. However, higher expression of $C s G D H, C s G S$ and $C s G O G A T$ potentially accelerated amino acid accumulation of tea plants, as reported in this study. Therefore, it concludes that AMF upregulated $C s G D H, C s G S$ and $C s G O G A T$ expression levels, to regulate amino acid biosynthesis.

HMGR is the first rate-limiting enzyme in the mevalonatepathway (MVA) of plants, which has an important impact on the metabolism of plant terpenes $(\mathrm{Li}$ et al., 2014). TCS1 is the main enzyme in caffeine biosynthesis of tea plants, which catalyzed the N-3 and N-1 to form methylation (Mizuno et al., 2003; Jin et al., 2016). In the present study, mycorrhizal inoculation significantly up-regulated the relative expression of leaf $C s H M G R$, and CsTCS1. It concludes that AM symbiosis upregulated CsHMGR and CsTCS1 to accelerate terpene and caffeine accumulation, although terpene and caffeine were not detected in this study.

APX is the main enzyme to effectively remove reactive oxygen species in plants, which improves plant resistance (Sarowar et al., 2005). Under adversity stress, plants usually upregulate the expression levels of one or more antioxidant enzyme genes, to enhance plant resistance ( $\mathrm{Hu}$ et al., 2012; Zhang et al., 2017). The changes in leaf CsAPX expression of tea plants under mycorrhization are in line with the result reported by Liu et al. (2011) in Cucumis sativus plants colonized by $F$. mosseae under low temperature conditions. Therefore, it could be speculated that AMF induces the expression of $C s A P X$ gene to regulate the adverse resistance of plants.

\section{Conclusions}

Claroideoglomus etunicatum, Diversispora spurca, $D$. versiformis and a mixture of the three AMF species could positively improve leaf food quality (sugars, total amino acid, total soluble protein, tea polyphenol, catechuic acid, and flavonoid) by means of upregulating relative expression of $C s G D H, C s G S, C s G O G A T, C s H M G R, C s A P X$ and CsTCS1 in the 'Fuding Dabaicha' seedlings. It supported the above hypothesis, namely, AMF colonization could improve food quality of tea plants through up-regulation of some potential gene expression. It seems to apply AMF as a biological agent to increase food quality of tea plants.

\section{Acknowledgements}

This study was supported by the Open Fund of State Key Laboratory of Tea Plant Biology and Utilization (SKLTOF20160112), the Science and Technology 
Foundation of Guizhou Province (2015[2155]), and the Key Agricultural Science and Technology Foundation of Guizhou Province ([2016]3006). It was also supported by the Long-Term Development Plan of University of Hradec Králové.

\section{References}

Aliasgharzad N, Hajiboland R, Olsson PA (2011). Lack of arbuscular mycorrhizal colonisation in tea (Camellia sinensis, $\mathrm{L}$.) plants cultivated in Northern Iran. Symbiosis 55(2):91-95.

Baslam M, Garmendia I, Goicoechea N (2013). The arbuscular mycorrhizal symbiosis can overcome reductions in yield and nutritional quality in greenhouse-lettuces cultivated at inappropriate growing seasons. Scientia Horticulturae 164:145-154.

Bradford MM (1976). A rapid and sensitive method for the quantification of microgram quantities of proteins utilizing the principle-dye binding. Analytical Biochemistry 72(1-2):248-252.

Burgess PJ, Carr MKV (1996). Responses of young tea (Camellia sinensis) clones to drought and temperature. I. yield and yield distribution. Experimental Agriculture 32(3):357-372.

Camenzind T, RilligMC (2013). Extraradical arbuscular mycorrhizal fungal hyphae in an organic tropical montane forest soil. Soil Biology and Biochemistry 64:96-102.

Cely MVT, de Oliveira, AG, de Freitas VF, de Luca MB, Barazetti AR, ... Andrade G (2016). Inoculant of arbuscular mycorrhizal fungi (Rhizophagus Clarus) increase yield of soybean and cotton under field conditions. Frontiers in Microbiology 7:720.

Chen S, Jin W, Liu A, Zhang S, Liu D, ... He C (2013). Arbuscular mycorrhizal fungi (AMF) increase growth and secondary metabolism in cucumber subjected to low temperature stress. Scientia Horticulturae 160:222-229.

Chen X, Li H, Chan WF, Wu C, Wu F, ... Wong MH (2012). Arsenite transporters expression in rice (Oryza sativa L.) associated with arbuscular mycorrhizal fungi (AMF) colonization under different levels of arsenite stress. Chemosphere 89(10):1248-1254.

Cheng SY, Wang Y, Fei Y, Zhu G (2004). Studies on the effects of different treatments on flavonoids contents in Ginkgo biloba leaves and their regulating mechanism. Journal of Fruit Science 21(2): 116-119.

Cicatelli A, Lingua G, Todeschini V, Biondi S, Torrigiani P, Castigione S (2012). Arbuscular mycorrhizal fungi modulate the leaf transcriptome of a Populus alba, L. clone grown on a zinc and copper-contaminated soil. Environmental \& Experimental Botany 75:25-35.

de La Rosa LA, Alvarez-Parrilla E, Shahidi F (2011). Phenolic compounds and antioxidant activity of kernels and shells of Mexican pecan (Carya illinoinensis). Journal of Agricultural and Food Chemistry 59(1):152162.

Fajardo L, Cáceres A, Arrindell P (2014). Arbuscular mycorrhizae, a tool to enhance the recovery and re-introduction of Juglans venezuelensis Manning, an endemic tree on the brink of extinction. Symbiosis 64(2):63-71.

GachomoE, Allen JW, Pfeffer PE, Govindarajulu M, ... Bücking H (2009). Germinating spores of Glomus intraradices can use internal and exogenous nitrogen sources for de novo biosynthesis of amino acids. New
Phytologist 184(2):399-411.

Hartmann H, Trumbore S (2016). Understanding the roles of nonstructural carbohydrates in forest trees-from what we can measure to what we want toknow. New Phytologist 211(2):386-403.

He JD, Dong T, Wu HH, Zou YN, Wu QS, Kuca K (2019). Mycorrhizas induce diverse responses of root TIP aquaporin gene expression to drought stress in trifoliate orange. Scientia Horticulturae 243:6469.

$\mathrm{Hu}$ L, Li H, Pang H, FuJ (2012). Responses of antioxidant gene, protein and enzymes to salinity stress in two genotypes of perennial ryegrass (Lolium perenne) differing in salt tolerance. Journal of Plant Physiology 169(2):146-156.

Hui T, Drijber RA, Li X, Miller DN, Wienhold BJ (2013). Arbuscular mycorrhizal fungi differ in their ability to regulate the expression of phosphate transporters in maize (Zea mays L.). Mycorrhiza 23(6):507514.

Jacob PT, Ana C, Concepción AA, Nuria F (2014). Transcriptional regulation of host $\mathrm{NH}_{4}^{+}$transporters and GS/GOGAT pathway in arbuscular mycorrhizal rice roots. Plant Physiology and Biochemistry 75:1-8.

Jin JQ, Yao MZ, Ma CL, MaJQ, Chen L (2016). Natural allelic variations of TCS1 play a crucial role in caffeine biosynthesis of tea plant and its related species. Plant Physiology and Biochemistry 100:18-26.

Kahneh E, RamezanPour H, Tanha MRH, Shirinfekr A (2006). Effect of arbuscular mycorrhizal fungi and phosphorus supplement on leaf $\mathrm{P}, \mathrm{Zn}$, $\mathrm{Cu}$ and $\mathrm{Fe}$ concentrations of tea seedlings. Caspian Journal of Environmental Sciences 4(1):53-58.

Kerio LC, Wachira FN, Wanyoko JK, Rotich MK (2013). Total polyphenols, catechin profiles and antioxidant activity of tea products from purple leaf coloured tea cultivars. Food Chemistry 136(3-4):14051413.

Larose G, Chênevert R, Moutoglis P, GagnéS, PichéY, VierheiligH (2002). Flavonoid levels in roots of Medicago sativa, are modulated by the developmental stage of the symbiosis and the root colonizing arbuscular mycorrhizal fungus. Journal of Plant Physiology 159(12):1329-1339.

Li YH, Lu JL, Fan FY, Shi YT (2014). Gene cloning and expression analysis of $H M G R$ in tea plant roots. Journal of Tea Science 34:583-590 (in Chinese with English abstract).

Lin ZH, Zhong QS, Chen CS (2012). Molecular cloning and quantitative analysis of $G D H, G S$ and $G O G A T$ genes from leave of tea plant.Journal of TeaScience 32:523-529 (in Chinese with English abstract).

Lingua G, Bona E, Manassero P, Marsano F, Todeschini V, ... Berta G (2013). Arbuscular mycorrhizal fungi and plant growth-promoting pseudomonads increases anthocyanin concentration in strawberry fruits (Fragaria $x$ ananassa var. Selva) in conditions of reduced fertilization. International Journal of Molecular Sciences 14(8):16207-16225.

Liu A, Chen S, Liu Y, Li Y, He C (2011). Effects of AM fungi on leat photosynthetic physiological parameters and antioxidant enzyme activities under low temperature. Acta Ecologica Sinica 31:3497-3503 (in Chinese with English abstract).

Liu CY, Wang P, Zhang DJ, Zou YN, Kuca K, Wu QS (2018). Mycorrhiza-induced change in root hair growth is associated with IAA accumulation and expression of EXPs in trifoliate orange under two $\mathrm{P}$ levels. Scientia Horticulturae 234:227-235. 
614

Livak KJ, Schmittgen TD (2001). Analysis of relative gene expression data using real-time quantitative PCR and $2^{-\Delta C T}$ method. Methods 25(4):402-408

Mena-Violante HG, Ocampo-Jiménez O, Dendooven L, Martínez-Soto G, González-Castañeda J, ... Olalde-Portugal V (2006). Arbuscular mycorrhizal fungi enhance fruit growth and quality of chile ancho (Capsicum annuum L. cv San Luis) plants exposed to drought. Mycorrhiza 16(4):261-267.

Mizuno K, Okuda A, Kato M, Yoneyama N, Tanaka H, ... Fujimura T (2003). Isolation of a new dual-functional caffeine synthase gene encoding an enzyme for the conversion of 7-methylxanthine to caffeine from coffee (Coffea arabica,L.).FEBSLetters 534(1-3):75-81.

Phillips JM, Hayman DS (1970). Improved procedures for clearing roots and staining parasitic and vesicular-arbuscular mycorrhizal fungi for rapid assessment of infection. Transactions of the British Mycological Society 55(1):158-161.

Ravnskov S, Wu Y, Graham JH (2003). Arbuscular mycorrhizal fungi differentially affect expression of genes coding for sucrose synthases in maize roots. New Phytologist 157(3):539-545.

Salvioli A, Zouari I, Chalot M, Bonfante P (2012). The arbuscular mycorrhizal status has an impact on the transcriptome profile and amino acid composition of tomato fruit. BMC Plant Biology 12(1):44.

Sanmartín C, Garmendia I, Romano B, Díaz M, Palop JA, Goicoechea N (2014). Mycorrhizal inoculation affected growth, mineral composition, proteins and sugars in lettuces biofortified with organic or inorganic selenocompounds. Scientia Horticulturae 180:40-51.

Sarowar S, Kim EN, Kim YJ, Ok SH, Kim KD, ... Shin JS (2005). Overexpression of a pepper ascorbate peroxidase-like 1 gene in tobacco plants enhances tolerance to oxidative stress and pathogens. Plant Science 169(1):55-63.

Sharma D, Kayang H (2017). Effects of arbuscular mycorrhizal fungi (AMF) on Camellia sinensis (L.) O. Kuntze under greenhouse conditions. Journal of Experimental Biology 5:235-241.

Shao YD, Zhang DJ, Hu XC, Wu QS, Jiang CJ, ... Kuča K (2018). Mycorrhiza-induced changes in root growth and nutrient absorption of tea plants. Plant Soil and Environment 64(6):283-289.

Singh S, Pandey A, Chaurasia B, Palni LMS (2008). Diversity of arbuscular mycorrhizal fungi associated with the rhizosphere of tea growing in 'natural' and 'cultivated' ecosites. Biology and Fertility of Soils 44(3):491500.

Singh S, Pandey A, Kumar B, Palni LMS (2010). Enhancement in growth and quality parameters of tea [Camellia sinensis (L.) O. Kuntze] through inoculation with arbuscular mycorrhizal fungi in an acid soil. Biology andFertility of Soils 46(5):427-433.
TchameniSN, Nwaga D, Wakam LN, Ngonkeu ELM,... Etoa FX(2012). Growth enhancement, amino acid synthesis and reduction in susceptibility towards phytophthora megakarya by arbuscular mycorrhizal fungi inoculation in cocoa plants. Journal of Phytopathology 160(5):220-228.

Van der Heijdan MGA, Kliromomos JN, Ursic M, Moutoglis P (1998). Mycorrhizal fungi diversity determines plant biodiversity, ecosystem variability and productivity. Nature 396(6706):69-72

Van Lelyveld LJ, Fraser C, Smith BL, Visse G (1990). Nitrogen fertilization of tea: effect of tea leaf plucking criteria on chlorophyll and quality parameters. South African Journal of Plant and Soil 7(3):188-191.

Vangelisti A, Natali L, Bernardi R, Sbrana C, Turrini A, ... Giordani T (2018). Transcriptome changes induced by arbuscular mycorrhizal fungi in sunflower (Helianthus annuus L.) roots. Scientific Reports $8(1): 4$.

Wu QS, Lou YG, Li Y (2015). Plant growth and tissue sucrose metabolism in the system of trifoliate orange and arbuscular mycorrhizal fungi. Scientia Horticulturae 181:189-193.

Wu QS, Peng YH, Zou YN, Liu CY (2010). Exogenous polyamines affect mycorrhizal development of Glomus mosseae-colonized citrus (Citrus tangerine) seedlings. ScienceAsia 36(3):254258.

Xia T, Gao LP (2009). Advances in biosynthesis pathways and regulation of flavonoids and catechins. Scientia Agricultura Sinica 42:2899-2908 (in Chinese with English abstract).

Zhang J, Zeng L, Sun H, Wu H, Chen S (2017). Adversity stress-related responses at physiological attributes, transcriptional and enzymatic levels after exposure to $\mathrm{Cu}$ in Lycopersicum esculentm seedlings. Scientia Horticulturae 222:213-220.

Zhao QH, Sun LT, Wang Y, Ding ZT, Li M (2014). Effects of arbuscular mycorrhizal fungi and nitrogen regimes on plant growth, nutrient uptake and tea quality in Camellia sinensis (L.) O. Kuntze. Plant Physiology Journal 50:164-170 (in Chinese with English abstract).

Zhao XM (2010). Sulfuric acid-vanillin assay of the total amount of tea catechin. Journal of Anhui Agricultural Sciences 38:9766-9770 (in Chinese with English abstract).

Zou YN, Srivastava AK, NiQD, Wu QS (2015).Disruption of mycorrhizal extraradical mycelium and changes in leaf water status and soil aggregate stability in rootbox-grown trifoliate orange. Frontiers in Microbiology 6:203.

Zubek S, Rola K, Szewczyk A, Majewska ML, Turnau K(2015). Enhanced concentrations of elements and secondary metabolites in Viola tricolor $\mathrm{L}$. induced by arbuscular mycorrhizal fungi. Plant and Soil 390(1-2):129142. 